\title{
State-of-the-art research on "Iymphomas: role of molecular imaging for staging, prognostic evaluation, and treatment response"
}

\author{
Lale Kostakoglu ${ }^{1}$ and Bruce D. Cheson ${ }^{2}$ \\ Department of Radiology, Mount Sinai Medical Center, New York, NY, USA \\ 2 Division of Hematology-Oncology, Lombardi Comprehensive Cancer Center, Georgetown University Hospital, Washington, DC, USA
}

Edited by:

Georgios S. Limouris, Athens

University Medical Faculty, Greece

\section{Reviewed by:}

Orazio Schillaci, University of Rome Tor Vergata, Italy

Vikram R. Lele, Jaslok Hospital and

Research Centre, India

\section{*Correspondence:}

Lale Kostakoglu, Department of Radiology, Mount Sinai Medical

Center, One Gustave Levy Place, Box

1141, New York, NY 10029, USA

e-mail: lale.kostakoglu@mssm.edu
Lymphomas are heterogeneous but potentially curable group of neoplasms. Treatment of lymphomas has rapidly evolved overtime with significant improvement in the cure rate and reductions in treatment-related toxicities. Despite excellent results, treatment programs are continued to be developed to achieve better curative and safety profiles. In these patients individualized therapy schemes can be devised based on a well-defined risk categorization. The therapy efficacy can be increased early during therapy in nonresponding patients with escalated therapy protocols or with the addition of radiation therapy, particularly, in advanced-stage or unfavorable risk patients. The increasing availability of positron emission tomography using 18F-fluorodeoxyglucose, particularly fused with computed tomography (FDG-PET/CT) has lead to the integration of this modality into the routine staging and restaging for lymphoma with convincing evidence that it is a more accurate imaging modality compared with conventional imaging techniques. FDG-PET/CT is also is a promising surrogate for tumor chemosensitivity early during therapy. This review will summarize published data on the utility of FDG-PET/CT imaging in the staging, restaging, and predicting therapy response in patients with lymphoma.

Keywords: PET/CT, Hodgkin lymphoma, non-Hodgkin lymphoma, interim-PET, response surrogate

\section{INTRODUCTION}

The lymphomas are a heterogeneous group of diseases with respect to their biology, treatment, and prognosis. Despite the high rate of cure of Hodgkin lymphoma (HL) and diffuse large B-cell lymphoma (DLBCL), there is a need to alter therapy in patients unlikely to benefit from standard treatment, while reducing treatment intensity in patients with low risk disease. To achieve this goal requires not only an accurate staging system, but strong baseline risk factors (prognostic), and/or those early during therapy (predictive factors) to define the optimal treatment strategy. Positron emission tomography (PET) using F-18fluorodeoxyglucose (FDG), integrated with computed tomography $(\mathrm{CT})(\mathrm{PET} / \mathrm{CT})$ has become widely used in the staging and evaluation of therapy response in lymphomas, and may provide the means for such an individualized approach.

\section{HISTOPATHOLOGIC LYMPHOMA SUBTYPES}

F-18-fluorodeoxyglucose-avidity varies among the various lymphoma subtypes, the most routinely avid being HL, DLBCL, Burkitt, mantle cell (MCL), follicular lymphoma (FL) with a PET/CT sensitivity of $85-100 \%$ (1-6). There is currently no established role for the clinical usefulness of FDG-PET/CT in the less common indolent NHLs including marginal zone lymphomas (MZL), chronic lymphocytic leukemia/small lymphocytic lymphoma (CLL/SLL), and lymphoplasmacytic lymphoma (LPL), that tend to have limited and variable FDG-avidity $(3,7-12)$. About $10 \%$ of NHLs are of T-cell origin (13) and FDG-PET avidity is variable; being most reliable for the more aggressive, nodal subtypes including peripheral T-cell lymphoma not otherwise specified and anaplastic large cell lymphoma $(12,13)$.

F-18-fluorodeoxyglucose-avidity appears to correlate with aggressiveness of lymphomas $(14,15)$ and imaging with FDGPET may be helpful in identifying a potential site of histologic transformation. It is important to note that SUVs exceeding 10 yields $80 \%$ certainty for the identification of aggressive behavior $(16,17)$, particularly, in Richter's transformation for patients with CLL/SLL (18).

\section{STAGING OF LYMPHOMAS}

Ann Arbor staging, the most widely used system, has evolved over the past 40 years to incorporate CT $(19,20)$. Nevertheless, anatomic imaging relies on size and location and, therefore, is unable to distinguish malignant from benign lymph nodes (21). Numerous studies and a meta-analysis demonstrate that FDG-PET is more accurate than $\mathrm{CT}$ at initial staging with a maximum joint sensitivity and specificity of $96 \%$ on a lesion basis (22), which far exceeded the corresponding values for contrast-enhanced computed tomography (CECT) $(2,9,22-26)$. Discordance between PET and CECT findings occurs in approximately one third of patients at initial staging, predominantly, in favor of PET/CT imaging $(22,24,26-32)$; however, stage is uncommonly altered (in up to $30 \%$ of patients), and treatment is rarely changed (in up to $15 \%$ of patients) with no evidence that outcome is improved as a result of these data $(2,24-29,36-42)$. It is important to realize that the 
widespread use of systemic chemotherapy in lymphoma patients appears to mitigate the need for a precise determination of the anatomic extent of disease; however, staging PET/CT is integral to evaluation of subsequent response to therapy.

The International Harmonization Project (IHP) recommends a baseline FDG-PET scan for HL and DLBCL because of their consistent FDG-avidity and potential curability (33). For other subtypes, FDG-PET imaging is recommended for clinical trials, particularly, when response rate is the primary objective. The current National Comprehensive Cancer Network guidelines (NCCN) recommend baseline PET imaging as an essential test in HL, DLBCL, AIDS related B-cell lymphomas and as a useful test in selected cases in FL, MZL, MCL, but does not recommend it in CLL/SLL $(34,35)$.

\section{PET PLUS CECT AT STAGING}

Whether the addition of a CECT improves the sensitivity and specificity of PET/CT remains controversial (24, 25, 32, 41-46). In a series of $103 \mathrm{NHL}$ and HL patients, Raanani et al. reported that the addition of CECT to PET/CT changed management in only about $10 \%$ of patients while FDG/PET resulted in a management change in almost $50 \%$ of HL patients compared with CECT alone (41). However this study described neither what type of treatment changes occurred nor whether outcome was altered. In a group of 47 NHL or HL patients, Rodríguez-Vigil et al. reported no significant differences between the use of unenhanced low-dose PET/CT and contrast-enhanced full-dose PET/CT, although PET/CECT produced fewer indeterminate findings and identified a higher number of extranodal sites (42). These results suggest a marginal benefit with the addition of CECT to PET examination. In current practice, management of lymphoma usually requires both CECT and low-dose FDG-PET/CT for morphologic and metabolic assessment, respectively. However, this strategy increases patient radiation exposure by up to twofold (45).

Contrast-enhanced computed tomography is advisable in patients with abdominal lymphomas for distinguishing lymph nodes from non-opacified bowel loops and vessels, and where more precise measuring of node size is indicated. In rare cases with head and neck involvement, CECT may be useful to differentiate physiologic uptake from enlarged cervical lymph nodes. While in lymphomas with variable and low-grade FDG uptake including CLL/SLL and MZL, and some PTCL (3, 8, 14, 47, 48), CECT should be the imaging modality of choice. Further consideration for the use of both FDG-PET and CECT includes patients who are planned to undergo radiation therapy.

\section{FDG-PET IN BONE MARROW INVOLVEMENT}

Accurate assessment of the BM is crucial because it often upstages disease, leading to alterations in therapy strategy $(5,6)$. Lymphoma involvement of the $\mathrm{BM}$ is more common in patients with NHL (20-30\%) $(49,50)$, especially, in indolent subtypes and MCL compared to those with HL (10\%). BM biopsy is known to have a substantial false-negative rate due to the small volume of samples (51), and that it does not evaluate marrow involvement outside the pelvis. The sensitivity of PET in detecting BM involvement in HL and NHL, primarily in DLBCL, is about 90 and 75\%, respectively (52-59) while only a sensitivity of $50 \%$ was achieved in indolent NHL $(52,53)$. The lower sensitivity seen in DLBCL can be explained by discordant lymphoid infiltrates representing the low-grade component of disease that lowers the sensitivity of FDG-PET imaging $(49,50)$. Although BMB remains essential for the diagnostic work-up only rarely do the early stage HL patients have BM involvement (58-60). BMB should no longer be recommended for staging clinically advanced HL because the marrow is virtually never involved in the absence of constitutional symptoms or other evidence of stage IV disease (60). Consequently, routine BMB should be restricted to patients with NHL. Patients with DLBCL rarely have a positive bone marrow biopsy in the absence of focal or diffuse involvement by PET-CT, or who have other evidence of advanced disease and, therefore, this procedure should be restricted to those with a positive scan to assess for the presence of a discordant histology. Even in indicated patients FDGPET should precede BMB and biopsy or MRI could be pursued for confirmation of a positive PET finding. In the post-therapy setting, one should be mindful of the reactive $\mathrm{BM}$ changes induced by the colony stimulating factors (i.e., G-CSF). A 4-6 week period of time should be allowed before post-therapy PET imaging in patients who have received G-CSF to minimize the risk of a false-positive interpretation of the BM.

\section{EVALUATION OF RESPONSE AFTER COMPLETION OF THERAPY}

Perhaps the clearest role for the use of PET in lymphoma is in post-treatment response assessment because of its ability to distinguish fibrosis or sclerosis from residual active disease. Early studies have demonstrated a role for post-therapy FDG-PET imaging in the prediction of aggressive NHL or HL recurrence (61-69). A negative (NPV) and a positive predictive value (PPV) of 80 and $100 \%$ were reported for FDG-PET in the identification of residual aggressive NHL after completion of first-line chemotherapy (66). In HL patients, studies demonstrate significantly shorter progression-free survivals (PFS) for PET-positive patients (0-4\%) compared with $85-95 \%$ for those with a negative scan $(62,63,68$, 69). The revised International Working Group response criteria (rIWG) incorporated FDG-PET to accurately assess post-therapy persistent masses in both NHL and HL (33). The rIWG-PET interpretation criteria (i.e., IHP criteria) eliminated the terminology of "complete remission/unconfirmed (CRu)" on the basis of better response characterization provided by FDG-PET imaging. However, there is a need to prospectively validate these criteria in $\mathrm{HL}$ and DLBCL after first-line therapy as the majority of prior studies using IHP were based on retrospective data.

\section{INDOLENT LYMPHOMAS}

Limited FDG-PET data exist for FDG-PET in low-grade NHL (7, 70-74). In 45 untreated FL patients, Le Dortz et al. reported a median PFS of 48 and 17.2 months in the PET/CT-negative and positive groups, respectively, after four or six cycles of induction immunochemotherapy (7). Similar results were obtained by Bishu et al. in a retrospective review of $31 \mathrm{FL}$ patients treated mainly with $\mathrm{R}-\mathrm{CHOP}$ therapy (70). In another series of 39 relapsed or refractory FL patients, after completion of bendamustine therapy, the percent reduction in SUVmax (70 vs. 29\%) and in maximum perpendicular diameters ( 78 vs. $48 \%$ ) were significantly greater in 
patients achieving a CR than in those with non-CR (71). The use of PET at the end-of-treatment in high-tumor-burden FL is supported by the emerging data. The utility of FDG-PET/CT in assessing response at the end of induction immunochemotherapy was suggested by the Primary Rituximab and Maintenance (PRIMA) study by the GELA in high-tumor-burden FL patients $(72,73)$. Patients remaining PET-positive had a significantly inferior PFS at 42 months than in those who became PET-negative (33 vs. $71 \%, p<0.001)$ in a subgroup of 122 patients (73). Similarly in a prospective study of 121 previously untreated high-tumor-burden FL patients at the end-of-treatment (first-line immunochemotherapy with six cycles of R-CHOP plus two cycles of rituximab, without rituximab maintenance) (74). When the response was assessed using Deauville criteria, with a median follow-up of 23 months, 2 year PFS was $87 \%$ for final PET-negative vs. 51\% for final PETpositive patients $(p<0.001)$, respectively. End-of-treatment, but not interim scans, were predictive of 2 year OS for positive and negative scans $(p=0.013)$.

\section{STEM CELL TRANSPLANTATION}

A current standard treatment for relapsed or refractory HL involves high-dose chemotherapy and autologous hematopoietic stem cell transplantation (HDT/ASCT), offering long-term disease free survival in more than $50 \%$ of transplanted patients (75). Favorable outcome is largely a function of chemosensitivity at the time of ASCT (76-84). In recent studies in HL, best ASCT response was obtained in patients with chemosensitive disease who were PET-negative (76-80) after salvage therapy regardless of the chemotherapy that induced the response (79). A recent metaanalysis from 12 studies with 630 patients (187 HL; 313 DLBCL) reported a sensitivity of $69 \%$ and specificity of $81 \%$ (83). Additionally, PET-positive disease was associated with a significantly inferior 3 year PFS or EFS (31-41\%) compared with patients who had PET-negative results following salvage chemotherapy prior to ASCT (75-82\%) (76-78). Similar results were obtained in a retrospective case-series of 39 primary refractory or relapsed DLBCL patients with 3 year PFS of 35 vs. $81 \%$ for patients with positive pre-ASCT PET vs. those who had a negative PET ( $p=0.003)(85)$. Consequently, post-salvage therapy FDG is recommended to differentiate patients with a better prognosis following ASCT from others with unfavorable prognosis.

\section{RESPONSE EVALUATION DURING THERAPY}

Rapid response to chemotherapy is a recognized surrogate marker of chemosensitivity in both HL and DLBCL with an attendant high likelihood of a longer PFS (86). Persistent FDG uptake after two to four cycles of chemotherapy is associated with relapse rates ranging from 50 to $100 \%$, while the relapse rate in interimPET-negative patients is usually lower than $10 \%$ (87-92). In a meta-analysis, interim FDG-PET yielded an overall sensitivity of $81 \%$ and a specificity of $97 \%$ for advanced-stage HL, and a sensitivity of $78 \%$ and a specificity of $87 \%$ for DLBCL (93). Nonetheless, more recently, the results obtained for DLBCL patients were less convincing (94).

In advanced-stage HL patients $(n=260)$, after two cycles (PET2) of standard therapy, Gallamini et al. reported treatment failure in $86 \%$ of PET2-positive patients after a median follow-up of 2.2 years while $95 \%$ of PET2-negative patients remained in CR (88). Interim-PET results have also been shown to be a stronger predictive factor for PFS than the International Prognostic Score (IPS) $(88,91)$. Similarly, in another non-randomized prospective study of mixed stage HL patients, Cerci et al. reported a 3-year EFS of 55 and $94 \%$ for PET2-positive and negative patients, respectively $(p<0.001)$ (95). However, these data should also be interpreted with caution because IPS categories were not restricted to advanced-stage patients and unfavorable factors were disregarded in the stage classification.

The role of FDG-PET in the prediction of ultimate outcome is clearer in advanced-stage than early stage HL (93-103). Hutchings et al. reported a PPV of only $30 \%$ for an interim-PET after two or three cycles of ABVD chemotherapy in early stage HL $(90,91)$ while the NPV was high at $95 \%$. More recently, in limited stage non-bulky HL patients the enthusiasm for interim-PET imaging has been tempered with no clear difference noted between PET2positive and negative patients with respect to PFS (87 vs. 91\%; $p=0.57$ ) (98). By contrast, end-chemotherapy PET was highly predictive of PFS (94 vs. 54\%; $p<0.0001$ ). However, these are retrospective data with no control imposed over PET acquisition protocols and standardization of timing which are essential factors to provide reliability and reproducibility for the results.

Another important consideration is that the effectiveness of therapy has an influence on the predictive value of any given predictive marker. Using a slightly less effective chemotherapy regimen (doxorubicin, vinblastine, and gemcitabine), in a nonrandomized prospective study of early non-bulky HL, Straus et al. reported a lower than expected 2 year PFS at $88 \%$ for PET2 negative patients while the PFS was $54 \%$ in the PET2-positive group $(p=0.0009),(96,97)$. Similarly, in a randomized, prospective trial by Le Roux et al. early and advanced-stage HL patients were treated with a therapeutic strategy adapted to baseline prognostic factors, interim-PET after four cycles of ABVD (PET4) and CECT (99). The negative NPV and PPV for the interim FDG-PET predicting 2 year PFS were 96 and 16\%, respectively $(p<0.0001)$. The inferior PPV obtained in this study is not surprising as treatment intensification schemes may negate the predictive value of PET positivity.

Based on compelling data on interim-PET in advanced-stage HL, multiple PET-directed randomized studies were initiated to determine the outcome of therapy escalation in non-responding patients as well as de-escalation in patients who achieve an early CR. But, only few have reported interim results (100-104). In the HD15 trial of the German Hodgkin Study Group (GHSG), HL patients (stages IIB, III, IV) were initially randomized to one of three induction regimens (102). Those with a residual mass of at least $2.5 \mathrm{~cm}$ underwent a PET scan. Patients with a negative study were not further treated, whereas those with a positive scan received involved field radiation. The frequency of consolidative IFRT was only $11 \%$ compared with $70 \%$ in prior studies antedating the use of PET scans, with no difference in overall survival. In a retrospective analysis of a prospective study by Gallamini et al. in advanced-stage HL (GITIL/HD0607) when the treatment of PET2-positive patients was escalated to BEACOPP (bleomycin, etoposide, adriamycin, cyclophosphamide, vincristine, procarbazine, and prednisone) regimen the FFS was 95\% in PET2 
negative and 62\% in PET2-positive groups $(p<0.0001)$ with a median follow-up of 34 months which was superior to the $15 \%$ in patients whose therapy was unchanged (103). Another adaptive therapy trial in advanced-stage HL by Dann et al. using not only interim-PET results but also the IPS for stratifying patients into different therapy arms reported a 10 -year PFS of $83 \%$ in interim-PET-positive patients compared with $93 \%$ for those with a negative interim-PET (ns) suggesting that unfavorable outcomes can be overcome by therapy intensification (100).

In the RAPID trial, patients with limited stage disease received three cycles of ABVD (104). Those who were PET-positive received an additional cycle followed by radiation therapy. The negative patients were randomized to involved field RT or observation, the latter being shown to be non-inferior. These results support the use of PET in risk-adapted strategies.

In DLBCL, while FDG-PET at completion of therapy is a good predictor of outcome, the value of an interim-PET remains controversial because of its low PPV (93). Although earlier studies supported a role for an interim FDG-PET performed after two to four cycles of standard chemotherapy, the results of these and later studies varied significantly among patient groups (105-107). The 2-year PFS for the PET-negative groups was $82-93 \%$ in PETnegative while the PFS for the PET-positive groups varied from 0 to $43 \%$. These differences in PET results may be related to varying follow-up periods, patient populations, and different types of treatments employed, i.e., standard chemotherapy alone or with immunotherapy (rituximab). To further clarify the clinical relevance of interim FDG-PET, in a risk-adapted dose-dense immunochemotherapy program, Moskowitz et al. reported similar PFS for interim-PET-positive/biopsy-negative patients and in interim-PET-negative patients during a follow-up of 44 months (94). In PET-positive patients, repeat biopsy was negative in $87 \%$, and $51 \%$ of these patients remained progression-free after consolidation therapy during follow-up.

To date, the majority of interim FDG-PET studies have used visual criteria. However, the results of the GELA trial (LNH20073B) of 85 high-risk DLBCL patients suggested that those patients whose tumors had a percent SUV change $(\triangle S U V \max )$ of $>66 \%$ between baseline and after two cycles of therapy ( 2 year PFS 77 vs. $57 \% ; p=0.028)$ and $>70 \%$ between baseline and after four cycles ( 2 year PFS 83 vs. $40 \%$; $p<0.0001$ ) could be spared high-dose therapy (108). On the contrary, outcomes did not differ significantly whether PET2 and PET4 were visually positive or negative. The GAINED trial by the same investigators is designed to further demonstrate the superiority of quantitative approach over visual interpretation (109).

In summary, in advanced-stage HL, encouraging data exist on the effectiveness of interim FDG-PET/CT as a surrogate for chemosensitivity. However, there is limited evidence that changing treatment based solely on interim-PET-CT results improves patient outcome. Interim-PET-adapted therapy strategies should be pursued only in a clinical trial setting until the value of interimPET is proven by ongoing prospective, "response-adapted" therapy trials. The role of FDG-PET in DLBCL and early stage HL are not supported by the available data. Furthermore, there is no evidence to suggest that an early therapy change in the poorly responding patients will translate into a survival benefit.

\section{SURVEILLANCE FOLLOWING FIRST-LINE THERAPY}

Despite improvements in survival rates, relapses occur in approximately $30-50 \%$ of advanced-stage HL and DLBCL patients following first-line therapy (110-112). In a meta-analysis, the sensitivity and specificity of FDG-PET in identifying disease relapse for HL were 50-100 and 67-100\%, respectively, and for NHL 33-77 and $82-100 \%$, respectively, irrespective of a residual mass on CT (113). In a recent study of $\mathrm{HL}$ and aggressive NHL, more than $60 \%$ of relapses were diagnosed clinically, especially, in aggressive NHL and in cases with extranodal involvement. Although HL relapses were more commonly detected by FDG-PET scans because of clinically silent disease, no survival benefit was proven (114). In another study of 421 patients with mixed histologies including HL, aggressive NHL, and FL after first complete remission, serial six monthly FDG-PET scans enabled detection of relapse within 18 months of therapy (115). There are also conflicting results reporting a PPV of only $30 \%$ for FDG-PET in HL patients (116).

In summary, survival does not appear to be affected by mode of detection of recurrent lymphoma or the frequency of imaging. The low PPV associated with follow-up FDG-PET scans negates their clinical value in identifying patients who would benefit from additional treatment $(117,118)$.

\section{GENERAL CONSIDERATIONS AND RECOMMENDATIONS TIMING OF FDG-PET IMAGING}

- Interim-PET should be scheduled within 4-5 days of start of the subsequent therapy cycle to minimize false-positive results produced by the florid inflammatory response that peaks at around day 10 of chemotherapy initiation $(118,119)$.

- The timing of FDG-PET studies after chemotherapy completion is more flexible, a 6- to 8-week window after end of therapy should be observed to allow for inflammation to subside and to minimize false-positive results caused by the inflammatory response associated with rituximab therapy (120).

- Although, the bulk of existing data supports the use of interimPET after two cycles of treatment in HL, there is no established optimal timing with regards to therapy cycles. If and when a paradigm shift toward tailored approach is established, performing PET after two cycles seems reasonable. There is also evidence that PET after one cycle has a high negative predictive value with respect to PFS $(121,122)$.

\section{STANDARDIZATION OF FDG-PET INTERPRETATION}

- The International Harmonization Project criteria were developed for evaluation of response after completion of therapy. IHP criteria use the mediastinal blood pool as an internal reference for lesions of $2.0 \mathrm{~cm}$ or larger to discriminate a positive finding from a negative (118).

- To increase the specificity of PET readings, the definition of a positive interim-PET result has evolved from any uptake above background to uptake intensity that is equal to the mediastinal blood pool, i.e., IHP criteria (118), and more recently to an intensity exceeding the background in the liver $(122,123)$.

- For interim-PET readings, a relatively high cut off is appropriate to measure chemosensitivity. Recently proposed "Deauville criteria" yield a flexible reading scheme suitable for different 
positivity thresholds to adjust for the intended treatment end-points $(122,123)$.

- Deauville criteria have recently been validated in a retrospective cohort of 260 advanced-stage HL patients treated with ABVD (124). After a mean follow-up of 27.2 months, the 3year PFS of PET2-positive and negative patients were 28 and $95 \%$, respectively $(p<0.001)$. The binary concordance between paired reviewers was high (k Cohen: 0.84 ).

- The widely recognized challenge to the integration of interimPET into management schemes is the variability and the high false-positive rates associated with visual evaluation, particularly in those with bulky residual masses.

\section{SEMI-QUANTITATIVE EVALUATION}

- Metabolic changes determined by the SUV which is adjusted for body weight and administered activity, provide a continuous and objective scheme of measurements that are more compatible with the kinetics of in vivo therapy response.

- The change in tumor SUVmax before and after treatment can be used as a measure of response. However, strict adherence to protocols for all imaging periods are necessary because SUV measurements depend on multiple variables including time interval after injection, blood glucose level, body weight, and technical PET parameters.

- The use of quantitation to improve upon visual assessment was explored in DLBCL after two and four cycles of chemotherapy by Casasnovas et al. $(108,125)$. The results of this study have

\section{REFERENCES}

1. Thill R, Neuerburg J, Fabry U, Cremerius U, Wagenknecht G, Hellwig D, et al. Comparison of findings with 18-FDG PET and CT in pretherapeutic staging of malignant lymphoma. Nuklearmedizin (1997) 36:234-9.

2. Buchmann I, Reinhardt M, Elsner $\mathrm{K}$, Bunjes D, Altehoefer C, Finke $\mathrm{J}$, et al. 2-(fluorine-18)fluoro-2deoxy-D-glucose positron emission tomography in the detection and staging of malignant lymphoma. A bicentertrial. Cancer (2001) 91:889-999. doi:10.1002/ 1097-0142(20010301)91:5<889:

:AID-CNCR1078>3.3.CO;2-X

3. Elstrom R, Guan L, Baker G, Nakhoda K, Vergilio JA, Zhuang $\mathrm{H}$, et al. Utility of FDG-PET scanning in lymphoma by WHO classification. Blood (2003) 101:3875-6. doi:10.1182/blood-2002-09-2778

4. Alavi A, Shrikanthan S, Aydin A, Talanow R, Schuster S. Fluorodeoxyglucosepositron-emission tomography findings in mantle cell lymphoma. Clin Lymphoma Myeloma Leuk (2011) 11:261-6. doi:10.1016/j.clml.2011.03.013

5. Brepoels L, Stroobants S, De Wever W, Dierickx D, Vandenberghe $\mathrm{P}$, Thomas J, et al. Positron emission tomography in mantle cell lymphoma. Leuk Lymphoma (2008) 49:1693-701. doi:10.1080/ 10428190802216707

6. Bodet-Milin C, Touzeau C, Leux C, Sahin M, Moreau A, Maisonneuve $\mathrm{H}$, et al. Prognostic impact of 18F-fluoro-deoxyglucose positron emission tomography in untreated mantle cell lymphoma: a retrospective study from the GOELAMS group. Eur J Nucl Med Mol Imaging (2010) 37:1633-42. doi:10.1007/ s00259-010-1469-2 S, Devillers A, Houot R, Rolland $\mathrm{Y}$, et al. Diagnostic and prognostic impact of (18)F-FDG PET/CT in follicular lymphoma. Eur J Nucl Med Mol Imaging (2010) 37. doi: 10.1007/s00259-010-1539-5

8. Wöhrer S, Jaeger $U$, Kletter $\mathrm{K}$, Becherer A, Hauswirth A, Turetschek K, et al. 18Ffluorodeoxy-glucose positron emission tomography (18FFDG-PET) visualizes follicular lymphoma irrespective of grading. Ann Oncol (2006) 17:780-4. doi:10.1093/annonc/mdl014

9. Jerusalem G, Beguin $Y$, Najjar F, Hustinx R, Fassotte MF, Rigo $\mathrm{P}$, et al. Positron emission tomography (PET) with 18Ffluorodeoxyglucose (18F-FDG)
7. Le Dortz L, De Guibert S, Bayat

been previously discussed in Section "Early Response Evaluation during Therapy."

- Further studies are needed to define a widely accepted semiquantitative approach for lymphoma, probably with slightly different values for each subtype.

\section{FUTURE DIRECTIONS IN QUANTITATIVE PET ASSESSMENTS}

- Disease bulk at initial presentation has long been a known adverse prognostic factor, particularly in early stage HL (126). Several methods can be used to measure disease bulk, including the mediastinal-thoracic ratio and maximum size of the largest mass. However, studies are underway to evaluate PETbased metabolic tumor volume (MTV) or total lesion glycolysis (TLG) as more accurate methods to determine disease burden by accounting for the whole body tumor volume using sophisticated software systems (127-130).

- Preliminary MTV data are available for patients with DLBCL $(131,132)$. In 169 stage II-III DLBCL patients treated with R$\mathrm{CHOP}$, multivariate analysis revealed an association between high MTV group and lower PFS and OS during a median followup of 36 months $(p<0.001)$, but not with stage III $(p=0.054)$ (131). These results suggest a higher predictive power for MTV compared to Ann Arbor staging in DLBCL patients.

- The prognostic value of these automated volumetric methods will be determined after the establishment of the optimal method for determining the most accurate tumor volume.

for the staging of low-grade nonHodgkin's lymphoma (NHL). Ann Oncol (2001) 12:825-30. doi:10.1023/A:1011169332265

10. Perry C, Herishanu Y, Metzer U, Bairey O, Ruchlemer R, Trejo L, et al. Diagnostic accuracy of PET/CT in patients with extranodal marginal zone MALT lymphoma. Eur J Haematol (2007) 79:205-9. doi:10.1111/j.1600-0609.2007. 00895.x

11. Tsukamoto N, Kojima M, Hasegawa $M$, Oriuchi N, Matsushima $\mathrm{T}$, Yokohama A, et al. The usefulness of $18 \mathrm{~F}$ fluorodeoxyglucose positron emission tomography (18F-FDG-PET) and a comparison of 18F-FDG-PET with 67 gallium scintigraphy in the evaluation of lymphoma: relation to histologic subtypes based on the World Health Organization classification. Cancer (2007) 110:652-9.

12. Weiler-Sagie M, Bushelev O, Epelbaum R, Dann EJ, Haim N, Avivi I, et al. 18F-FDG avidity in lymphoma readdressed: a study of 766 patients. $\mathrm{J} \mathrm{Nucl}$ Med (2010) 51:25-30. doi:10. 2967/jnumed.109.067892

13. Kako S, Izutsu K, Ota Y, Minatani Y, Sugaya M, Momose T, et al. FDG-PET in T-cell and NK-cell neoplasms. Ann Oncol (2007) 18:1685-90. doi:10.1093/annonc/ $\operatorname{mdm} 265$

14. Tan D, Horning SJ. Follicular lymphoma: clinical features and treatment. Hematol Oncol Clin North Am (2008) 22:863-82. doi: 10.1016/j.hoc.2008.07.013

15. Montoto S, Davies AJ, Matthews J, Calaminici M, Norton AJ, Amess J, et al. Risk and clinical implications of transformation of follicular lymphoma to diffuse large B-cell lymphoma. J Clin Oncol (2007) 25:2426-33. doi:10.1200/ JCO.2006.09.3260

16. Noy A, Schöder $H$, Gönen $M$, Weissler M, Ertelt K, Cohler C, et al. The majority of transformed lymphomas have high standardized uptake values (SUVs) on positron emission tomography (PET) scanning similar to diffuse large Bcell lymphoma (DLBCL). Ann Oncol (2009) 20:508-12. doi:10. 1093/annonc/mdn657

17. Schöder H, Noy A, Gönen M, Weng L, Green D, Erdi YE, et al. Intensity of 18 fluorodeoxyglucose uptake in positron emission tomography distinguishes between indolent and aggressive nonHodgkin's lymphoma. J Clin Oncol (2005) 23:4643-51. doi:10.1200/ JCO.2005.12.072 
18. Bruzzi JF, Macapinlac H, Tsimberidou AM, Truong MT, Keating MJ, Marom EM, et al. Detection of Richter's transformation of chronic lymphocytic leukemia by PET/CT. J Nucl Med (2006) 47:1267-73.

19. Lister TA, Crowther D, Sutcliffe SB, Glatstein E, Canellos GP, Young $\mathrm{RC}$, et al. Report of a committee convened to discuss the evaluation and staging of patients with Hodgkin's disease: Cotswald meeting. J Clin Oncol (1989) 7:1630-6.

20. Rosenberg S. Validity of the Ann Arbor staging system classification for the non-Hodgkin's lymphomas. Cancer Treat Rep (1977) 61:1023-7.

21. Nyman R, Forsgren G, Glimelius B. Long-term follow-up of residual mediastinal masses in treated Hodgkin's disease using MR imaging. Acta Radiol (1996) 37:323-6. doi:10.3109/02841859609177659

22. Isasi CR, Lu P, Blaufox MD. A metaanalysis of 18F-2-deoxy2-fluoro-D-glucose positron emission tomography in the staging and restaging of patients with lymphoma. Cancer (2005) 104:106674. doi:10.1002/cncr.21253

23. Moog F, Bangerter M, Diederichs CG, Guhlmann A, Merkle E, Frickhofen N, et al. Extranodal malignant lymphoma: detection with FDG PET versus CT. Radiology (1998) 206:475-81.

24. Hutchings M, Loft A, Hansen M, Pedersen LM, Berthelsen AK, Kei$\operatorname{ding} \mathrm{S}$, et al. Position emission tomography with or without computed tomography in the primary staging of Hodgkin's lymphoma. Haematologica (2006) 91:482-9.

25. Schaefer NG, Hany TF, Taverna C, Seifert B, Stumpe KD, von Schulthess GK, et al. Non-Hodgkin lymphoma and Hodgkin disease: coregistered FDG PET and CT at staging and restaging - do we need contrast-enhanced CT? Radiology (2004) 232:823-9. doi:10. 1148/radiol.2323030985

26. Naumann R, Beuthien-Baumann B, Reiss A, Schulze J, Hänel A, Bredow J, et al. Substantial impact of FDG-PET imaging on the therapy decision in patients with earlystage Hodgkin's lymphoma. $\mathrm{Br} J$ Cancer (2004) 90:620-5. doi:10. 1038/sj.bjc.6601561

27. Bangerter M, Moog F, Buchmann I, Kotzerke J, Griesshammer $M$, Hafner $M$, et al. Wholebody 2-[18F]-fluoro-2-deoxy-Dglucose positron emission tomography (FDG-PET) for accurate staging of Hodgkin's disease. Ann Oncol (1998) 9:1117-22. doi:10. 1023/A:1008486928190

28. Weihrauch MR, Re D, Bischoff S, Dietlein M, Scheidhauer K, Krug $\mathrm{B}$, et al. Whole-body positron emission tomography using $18 \mathrm{~F}$ fluorodeoxyglucose for initial staging of patients with Hodgkin's disease. Ann Hematol (2002) 81:20-5. doi:10.1007/s00277-001-0390-y

29. Jerusalem G, Beguin Y, Fassotte MF, Najjar F, Paulus P, Rigo $\mathrm{P}$, et al. Whole-body positron emission tomography using $18 \mathrm{~F}-$ fluorodeoxyglucose compared to standard procedures for staging patients with Hodgkin's disease. Haematologica (2001) 86:266-73.

30. Picardi M, Soricelli A, Grimaldi F, Nicolai E, Gallamini A, Pane F. Fused FDG-PET/contrastenhanced CT detects occult subdiaphragmatic involvement of Hodgkin's lymphoma thereby identifying patients requiring six cycles of anthracyclinecontaining chemotherapy and consolidation radiation of spleen. Ann Oncol (2011) 22:671-80. doi:10.1093/annonc/mdq403

31. Carr R, Barrington SF, Madan B, O'Doherty MJ, Saunders CA, van der Walt J, et al. Detection of lymphoma in bone marrow by wholebody positron emission tomography. Blood (1998) 91:3340-6.

32. Tatsumi M, Cohade C, Nakamoto Y, Fishman EK, Wahl RL. Direct comparison of FDG PET and CT findings in patients with lymphoma: initial experience. Radiology (2005) 237:1038-45. doi:10. 1148/radiol.2373040555

33. Cheson BD, Pfistner B, Juweid ME, Gascoyne RD, Specht L, Horning SJ, et al. Revised response criteria for malignant lymphoma. J Clin Oncol (2007) 25:579-86. doi:10. 1200/JCO.2006.09.2403

34. National Comprehensive Cancer Network. Hodgkin Lymphoma. NCCN v2 (2012). Available at: http: //www.nccn.org/professionals/ physician_gls/pdf/hodgkins.pdf

35. National Comprehensive Cancer Network. NonHodgkin Lymphoma. NCCN v3 (2012). Available at: http: //www.nccn.org/professionals/ physician_gls/pdf/nhl.pdf

36. Partridge S, Timothy A, O’Doherty MJ, Hain SF, Rankin S, Mikhaeel G. 2-Fluorine-18-fluoro-2-deoxyD glucose positron emission tomography in the pretreatment staging of Hodgkin disease: influence on patient management in a single institution. Ann Oncol (2000) 11:1273-9. doi:10.1023/A:1008368330519

37. Pelosi E, Pregno P, Penna D, Deandreis D, Chiappella A, Limerutti G, et al. Role of whole body $[18 \mathrm{~F}]$ fluorodeoxyglucose positron emission tomography/computed tomography (FDG-PET/CT) and conventional techniques in the staging of patients with Hodgkin and aggressive non-Hodgkin lymphoma. Radiol Med (2008) 113:578-90. doi:10.1007/s11547-008-0264-7

38. Rigacci L, Vitolo U, Nassi L, Merli F, Gallamini A, Pregno P, et al. Positron emission tomography in the staging of patients with Hodgkin's lymphoma: a prospective multicentric study by the Intergruppo Italiano Linfomi. Ann Hematol (2007) 86:897-903. doi: 10.1007/s00277-007-0356-9

39. Wirth A, Seymour JF, Hicks RJ, Ware R, Fisher R, Prince M, et al. Fluorine-18 flurordeoxyglucose positron emission tomography, gallium-67 scintigraphy, and conventional staging for Hodgkin's disease and non-Hodgkin's lymphoma. Am J Med (2002) 112:262-8. doi:10.1016/S00029343(01)01117-2

40. Munker R, Glass J, Griffeth LK, Sat$\operatorname{tar} \mathrm{T}$, Zamani R, Heldmann M, et al. Contribution of PET imaging to the initial staging and prognosis of patients with Hodgkin's disease. Ann Oncol (2004) 15:1699704. doi:10.1093/annonc/mdh426

41. Raanani P, Shasha Y, Perry C, Metser U, Naparstek E, Apter S, et al. Is CT scan still necessary for staging in Hodgkin and non-Hodgkin lymphoma patients in the PET/CT era? Ann Oncol (2006) 17:117-22. doi:10.1093/ annonc/mdj024

42. Rodríguez-Vigil B, Gómez-León N, Pinilla I, Hernández-Maraver D, Coya J, Martín-Curto L, et al. PET/CT in lymphoma: prospective study of enhanced full-dose PET/CT versus unenhanced low dose PET/CT. J Nucl Med (2006) 47:1643-8.

43. Kabickova E, Sumerauer D, Cumlivska E, Drahokoupilova E, Nekolna M, Chanova M, et al. Comparison of 18F-FDG-PET and standard procedures for the pretreatment staging of children and adolescents with Hodgkin's disease. Eur J Nucl Med Mol Imaging (2006) 33:1025-31. doi:10.1007/s00259-005-0019-9
44. Elstrom RL, Leonard JP, Coleman M, Brown RK. Combined PET and low-dose, noncontrast CT scanning obviates the need for additional diagnostic contrastenhanced CT scans in patients undergoing staging or restaging for lymphoma. Ann Oncol (2008) 19:1770-3. doi:10.1093/ annonc/mdn282

45. Brix G, Lechel U, Glatting G, Ziegler SI, Münzing W, Müller SP, et al. Radiation exposure of patients undergoing whole-body dual-modality 18F-FDG PET/CT examinations. J Nucl Med (2005) 46:608.

46. Pinilla I, Gómez-León N, Del Campo-Del Val L, et al. Diagnostic value of CT, PET and combined PET/CT performed with low-dose unenhanced CT and fulldose enhanced CT in the initial staging of lymphoma. Q J Nucl Med Mol Imaging (2011) 55:56775.

47. Beal KP, Yeung HW, Yahalom J. FDG-PET scanning for detection and staging of extranodal marginal zone lymphomas of the MALT type: a report of 42 cases. Ann Oncol (2005) 16:473-80. doi:10. 1093/annonc/mdi093

48. Hoffmann M, Wöhrer S, Becherer A, Chott A, Streubel B, Kletter $\mathrm{K}$, et al. 18F-fluoro-deoxyglucose positron emission tomography in lymphoma of mucosaassociated lymphoid tissue: histology makes the difference. Ann Oncol (2006) 17:1761-5. doi:10. 1093/annonc/mdl295

49. Chung R, Lai R, Wei P, Lee J, Hanson J, Belch AR, et al. Concordant but not discordant bone marrow involvement in diffuse large B-cell lymphoma predicts a poor clinical outcome independent of the International prognostic index. Blood (2007) 110:1278-82. doi:10.1182/ blood-2007-01-070300

50. Campbell J, Seymour JF, Matthews J, Wolf $\mathrm{M}$, Stone J, Juneja S. The prognostic impact of bone marrow involvement in patients with diffuse large cell lymphoma varies according to the degree of infiltration and presence of discordant marrow involvement. J Eur J Haematol (2006) 76:473. doi:10.1111/j.1600-0609.2006 00644.x

51. Pakos EE, Fotopoulos AD, Ioannidis JP. 18F FDG PET for evaluation of bone marrow infiltration in staging of lymphoma: a meta-analysis. J Nucl Med (2005) 46:958-63. 
52. Wu LM, Chen FY, Jiang XX, Gu HY, Yin Y, Xu JR. (18)F-FDG PET, combined FDG-PET/CT and MRI for evaluation of bone marrow infiltration in staging of lymphoma: a systematic review and meta-analysis. Eur J Radiol (2012) 8:303-11. doi:10.1016/j. ejrad.2010.11.020

53. Wang J, Weiss LM, Chang KL, Slovak ML, Gaal K, Forman SJ, et al. Diagnostic utility of bilateral bone marrow examination: significance of morphologic and ancillary technique study in malignancy. Cancer (2002) 94:1522-31. doi:10.1002/ cncr.10364

54. Chen YK, Yeh CL, Tsui CC, Liang JA, Chen JH, Kao CH. F-18 FDG PET for evaluation of bone marrow involvement in non-Hodgkin lymphoma: a meta-analysis. Clin Nucl Med (2011) 36:553-9. doi:10. 1097/RLU.0b013e318217aeff

55. Cheng G, Chen W, Chamroonrat W, Torigian DA, Zhuang H, Alavi A. Biopsy versus FDG PET/CT in the initial evaluation of bone marrow involvement in pediatric lymphoma patients. Eur J Nucl Med Mol Imaging (2011) 38:1469-76. doi:10.1007/s00259-011-1815-z

56. Shaefer NG, Strobel K, Taverna C, Hany T. Bone involvement in patients with lymphoma: the role of FDG-PET/CT. Eur J Nucl Med Mol Imaging (2007) 34:60-7. doi: 10.1007/s00259-006-0238-8

57. Núñez R, Rini JN, Tronco GG, Tomas MB, Nichols K, Palestro CJ. Correlation of hematologic parameters with bone marrow and spleen uptake in FDG PET. Rev Esp Med Nucl (2005) 24:107-12.

58. Salaun PY, Gastinne T, BodetMilin C, Campion L, Cambefort P, Moreau A, et al. Analysis of 18F-FDG PET diffuse bone marrow uptake and splenic uptake in staging of Hodgkin's lymphoma: a reflection of disease infiltration or just inflammation? Eur J Nucl Med Mol Imaging (2009) 36:1813. doi:10.1007/s00259-009-1183-0

59. El-Galaly TC, d'Amore F, Mylam KJ, de NullyBrownP, Bøgsted M, Bukh A, et al. Routine bone marrow biopsy has little or no therapeutic consequence for positron emission tomography/computed tomography-staged treatmentnaive patients with Hodgkin lymphoma. J Clin Oncol (2012) 30:4508-14. doi:10.1200/JCO

60. Richardson SE, Sudak J, Warbey V, Ramsay A, McNamara CJ. Routine bone marrow biopsy is not necessary in the staging of patients with classical Hodgkin lymphoma in the 18F-fluoro2-deoxyglucose positron emission tomography era. Leuk Lymphoma (2012) 53:381-5. doi:10 3109/10428194.2011.616613

61. Radford JA, Cowan RA, Flanagan M, Dunn G, Crowther D, Johnson RJ, et al. The significance of residual mediastinal abnormality on the chest radiograph following treatment for Hodgkin disease. J Clin Oncol (1988) 6:940-6.

62. Zinzani PL, Magagnoli M, Chierichetti F, Zompatori M, Garraffa G, Bendandi $M$, et al. The role of positron emission tomography (PET) in the management of lymphoma patients. Ann Oncol (1999) 10:1181-4. doi:10.1023/A:1008327127033

63. Cremerius U, Fabry U, Neuerburg J, Zimny M, Osieka R, Buell U. Positron emission tomography with 18 F-FDG to detect residual disease after therapy for malignant lymphoma. Nucl Med Commun (1998) 19:1055-63. doi:10. 1097/00006231-199811000-00005

64. Mikhaeel NG, Timothy AR, O'Doherty MJ, Hain S, Maisey MN. 18-FDG-PET as a prognostic indicator in the treatment of aggressive Non-Hodgkin's Lymphomacomparison with CT. Leuk Lymphoma (2000) 2000(39):543-53. doi:10.3109/10428190009113384

65. Dittmann H, Sokler M, Kollmannsberger C, Dohmen BM, Baumann C, Kopp A, et al. Comparison of 18FDG-PET with CT scans in the evaluation of patients with residual and recurrent Hodgkin's lymphoma. Oncol Rep (2001) 8:1393-9.

66. Spaepen K, Stroobants S, Dupont P, Van SteenweghenS, Thomas J, Vandenberghe P, et al. Prognostic value of positron emission tomography (PET) with fluorine-18 fluorodeoxyglucose $\left(\left[{ }^{18} \mathrm{~F}\right] \mathrm{FDG}\right.$ after first line chemotherapy in non-Hodgkins lymphoma: is ( $\left[{ }^{18} \mathrm{~F}\right]$ FDG PET a valid alternative to conventional diagnostic methods? J Clin Oncol (2001) 19:414-9.

67. Mikhaeel NG, Mainwaring $P$, Nunan T, Timothy AR. Prognostic value of interim and post treatment FDG-PET scanning in Hodgkin lymphoma [abstract]. Ann Oncol (2002) 13(Suppl 2):21.

68. Wiedmann E, Baican B, Hertel A, Baum RP, Chow KU, Knupp B, et al. Positron emission tomography
(PET) for staging and evaluation of response to treatment in patients with Hodgkin's disease. Leuk Lymphoma (1999) 34:545-51.

69. Hueltenschmidt B, Sautter-Bihl ML, Lang O, Maul FD, Fischer J, Mergenthaler HG, et al. Whole body positron emission tomography in the treatment of Hodgkin disease. Cancer (2001) 91:302-10. doi:10.1002/10970142(20010115)91:2<302::AIDCNCR1002>3.3.CO;2-W

70. Bishu S, Quigley JM, Bishu SR, Olsasky SM, Stem RA, Shostrom VK, et al. Predictive value and diagnostic accuracy of F-18-fluorodeoxy-glucose positron emission tomography treated grade 1 and 2 follicular lymphoma. Leuk Lymphoma (2007) 48:1548-55. doi:10. 1080/10428190701344915

71. Tateishi U, Tatsumi M, Terauchi T, Ishizawa K, Ogura M, Tobinai $\mathrm{K}$. Relevance of monitoring metabolic reduction in patients with relapsed or refractory follicular and mantle cell lymphoma receiving bendamustine: a multicenter study. Cancer Sci (2011) 102:4148. doi:10.1111/j.1349-7006.2010. 01802.x

72. Salles G, Seymour JF, Offner F, López-Guillermo A, Belada D, Xerri L, et al. Rituximab maintenance for 2 years in patients with high tumour burden follicular lymphoma responding to rituximab plus chemotherapy (PRIMA): a phase 3, randomised controlled trial. Lancet (2011) 377:42-51. doi:10.1016/S01406736(10)62175-7

73. Trotman J, Fournier M, Lamy T, Seymour JF, Sonet A, Janikova A, et al. Positron emission tomographycomputed tomography (PET-CT) after induction therapy is highly predictive of patient outcome in follicular lymphoma: analysis of PET-CT in a subset of PRIMA trial participants. J Clin Onco (2011) 29:3194-200. doi:10.1200/ JCO.2011.35.0736

74. Dupuis J, Berriolo-Riedinger A, Julian A, Brice P, TychyjPinel C, Tilly $\mathrm{H}$, et al. Impact of [18F]fluorodeoxyglucose positron emission tomography response evaluation in patients with high-tumor burden follicular lymphoma treated with immunochemotherapy: a prospective study from the Grouped'Etudes des Lymphomes de l'Adulte and GOELAMS. J Clin Oncol (2012) 30:4317-22. doi:10.1200/JCO.2012.43.0934
75. Brice P, Bouabdallah R, Moreau P, Divine M, André M, Aoudjane $M$, et al. Prognostic factors for survival after high-dose therapy and autologous stem cell transplantation for patients with relapsing Hodgkin's disease: analysis of 280 patients from the French registry. Société Française de Greffe de Moëlle. Bone Marrow Transplant (1997) 20:21-6. doi:10.1038/ sj.bmt. 1700838

76. Moskowitz $\mathrm{CH}$, Yahalom J Zelenetz AD, Zhang Z, Filippa D, Teruya-Feldstein J, et al. Highdose chemo-radiotherapy for relapsed or refractory Hodgkin lymphoma and the significance of pre-transplant functional imaging. $\mathrm{Br} J$ Haematol (2010) 148:890-7. doi:10.1111/j.13652141.2009.08037.x

77. Smeltzer JP, Cashen AF, Zhang Q, Homb A, Dehdashti F, Abboud $\mathrm{CN}$, et al. Prognostic significance of FDG-PET in relapsed or refractory classical Hodgkin lymphoma treated with standard salvage chemotherapy and autologous stem cell transplantation. Biol Blood Marrow Transplant (2011) 11:1646-52. doi:10.1016/j. bbmt.2011.04.011

78. Moskowitz AJ, Yahalom J, Kewalramani T, Maragulia JC, Vanak JM, Zelenetz AD, et al. Pretransplantation functional imaging predicts outcome following autologous stem cell transplantation for relapsed and refractory Hodgkin lymphoma. Blood (2010) 116:4934-7. doi:10.1182/ blood-2010-05-282756

79. Moskowitz $\mathrm{CH}$, Matasar MJ, Zelenetz AD, Nimer SD, Gerecitano J, Hamlin $\mathrm{P}$, et al. Normalization of pre-ASCT, FDGPET imaging with second-line, non-cross-resistant, chemotherapy programs improves eventfree survival in patients with Hodgkin lymphoma. Blood (2012) 119:1665-70. doi:10.1182/blood2011-10-388058

80. Sucak GT, Özkurt ZN, Suyani E, Yasar DG, Akdemir ÖÜ, Aki Z, et al. Early post-transplantation positron emission tomography in patients with Hodgkin lymphoma is an independent prognostic factor with an impact on overall survival. Ann Hematol (2011) 90:1329-36. doi:10.1007/s00277011-1209-0

81. Schot B, van ImhoffG, Pruim J, Sluiter W, Vaalburg W, Vellenga E. Predictive value of early positron emission tomography 
in chemosensitive relapsed lymphoma. Br J Haematol (2003) 123:282-7. doi:10.1046/j.13652141.2003.04593.x

82. Schot BW, Zijlstra JM, Sluiter WJ, van ImhoffGW, Pruim J, Vaalburg W, et al. Early FDG-PET assessment in combination with clinical risk scores determines prognosis in recurring lymphoma. Blood (2007) 109:486-91. doi:10.1182/ blood-2005-11-006957

83. Terasawa T, Dahabreh IJ, Nihashi T. Fluorine-18-fluorodeoxyglucose positron emission tomography in response assessment before high-dose chemotherapy for lymphoma: a systematic review and meta-analysis. Oncologist (2010) 15:750-9. doi:10.1634/ theoncologist.2010-0054

84. Poulou LS, Thanos L, Ziakas PD. Unifying the predictive value of pretransplant FDG PET in patients with lymphoma: a review and meta-analysis of published trials. Eur J Nucl Med Mol Imaging (2010) 37:156-62. doi:10.1007/ s00259-009-1258-y

85. Dickinson M, Hoyt R, Roberts AW, Grigg A, Seymour JF, Prince $\mathrm{HM}$, et al. Improved survival for relapsed diffuse large B cell lymphoma is predicted by a negative pre-transplant FDG-PET scan following salvage chemotherapy. Br J Haematol (2010) 150:3945. doi:10.1111/j.1365-2141.2010. 08162.x

86. Haw R, Sawka CA, Franssen E, Berinstein HL. Significance of a partial or slow response to frontline chemotherapy in the management of intermediate-grade or high-grade non-Hodgkin's lymphoma: a literature review. J Clin Oncol (1994) 12:1074-84.

87. Gallamini A, Rigacci L, Merli F, Nassi L, Bosi A, Capodanno I, et al. The predictive value of positron emission tomography scanning performed after two courses of standard therapy on treatment outcome in advanced stage Hodgkin's disease. Haematologica (2006) 91:475-81.

88. Gallamini A, Hutchings M, Rigacci L, Specht L, Merli F, Hansen M, et al. Early interim 2-[18F]fluoro2-deoxy-D-glucose positron emission tomography is prognostically superior to international prognostic score in advancedstage Hodgkin's lymphoma: a report from a joint Italian-Danish study. J Clin Oncol (2007) 25: 3746-52. doi:10.1200/JCO.2007. 11.6525
89. Zinzani PL, Tani M, Fanti S, Alinari L, Musuraca G, Marchi E, et al. Early positron emission tomography (PET) restaging: a predictive final response in Hodgkin's disease patients. Ann Oncol (2006) 17:1296-300. doi:10. 1093/annonc/mdl122

90. Hutchings M, Mikhaeel NG, Fields PA, Nunan T, Timothy AR. Prognostic value of interim FDG-PET after two or three cycles of chemotherapy in Hodgkin lymphoma. Ann Oncol (2005) 16:1160-8. doi:10.1093/annonc/mdi200

91. Hutchings M, Loft A, Hansen M, Pedersen LM, Buhl T, Jurlander J, et al. FDG-PET after two cycles of chemotherapy predicts treatment failure and progression-free survival in Hodgkin lymphoma. Blood (2006) 107:52-9. doi:10. 1182/blood-2005-06-2252

92. Zinzani PL, Rigacci L, Stefoni V, Broccoli A, Puccini B, Castagnoli A, et al. Early interim 18F-FDG PET in Hodgkin's lymphoma: evaluation on 304 atients. Eur J Nucl Med Mol Imaging (2012) 39:4-12. doi:10.1007/s00259-011-1916-8

93. Terasawa T, Lau J, Bardet S, Couturier O, Hotta T, Hutchings $M$, et al. Fluorine-18fluorodeoxyglucose positron emission tomography for interim response assessment of advancedstage Hodgkin's lymphoma and diffuse large B-cell lymphoma: a systematic review. $J$ Clin Oncol (2009) 27:1906-14. doi:10.1200/JCO.2008.16.0861

94. Moskowitz CH, Schöder H, Teruya-Feldstein J, Sima C, Iasonos A, Portlock CS, et al. Risk-adapted dose-dense immunochemotherapy determined by interim FDG-PET in advanced-stage diffuse large B-Cell lymphoma. $J$ Clin Oncol (2010) 28:1896-903. doi:10.1200/JCO.2009.26.5942

95. Cerci JJ, Pracchia LF, Linardi CC, Pitella FA, Delbeke D, Izaki M, et al. 18F-FDG PET after 2 cycles of ABVD predicts event-free survival in early and advanced Hodgkin lymphoma. J Nucl Med (2010) 51:1337-43. doi:10.2967/jnumed. 109.073197

96. Straus DJ, Johnson JL, LaCasce AS, Bartlett NL, Kostakoglu L, Hsi ED, et al. Doxorubicin, vinblastine, and gemcitabine (CALGB 50203) for stage I/II nonbulky Hodgkin lymphoma: pretreatment prognostic factors and interim PET. Blood (2011) 117:5314-20. doi:10.1182/ blood-2010-10-314260
97. Kostakoglu L, Schöder H, Johnson JL, Hall NC, Schwartz LH, Straus DJ, et al. Interim FDG pet imaging in CALGB 50203 trial of stageI/II non-bulky Hodgkin lymphoma: would using combined PET and CT criteria better predict response than each test alone? Leuk Lymphoma (2012) 53:2143-50. doi:10. 3109/10428194.2012.676173

98. Barnes JA, LaCasce AS, Zukotynski K, Israel D, Feng Y, Neuberg $\mathrm{D}$, et al. End-of-treatment but not interim PET scan predicts outcome in nonbulky limitedstage Hodgkin's lymphoma. Ann Oncol (2011) 22:910-5. doi:10. 1093/annonc/mdq549

99. Le RouxPY, Gastinne T, Le Gouills, Nowak E, Bodet-Milin C, Querellou $S$, et al. Prognostic value of interim FDG PET/CT in Hodgkin's lymphoma patients treated with interim response-adapted strategy: comparison of International Harmonization Project (IHP), Gallamini and London criteria. Eur J Nucl Med Mol Imaging (2011) 38:1064-71. doi:10.1007/s00259011-1741-0

100. Dann EJ, Blumenfeld Z, BarShalom R, Avivi I, Ben-Shachar $\mathrm{M}$, Goor O, et al. 10-year experience with treatment of high and standard risk Hodgkin disease: six cycles of tailored BEACOPP, with interim scintigraphy, are effective and female fertility is preserved. Am J Hematol (2012) 87:32-6. doi: 10.1002/ajh.22187

101. Avigdor A, Bulvik S, Levi I, Dann EJ, Shemtov N, Perez-Avraham $\mathrm{G}$, et al. Two cycles of escalated BEACOPP followed by four cycles of ABVD utilizing earlyinterim PET/CT scan is an effective regimen for advanced highrisk Hodgkin's lymphoma. Ann Oncol (2010) 21:126-32. doi:10. 1093/annonc/mdp271

102. Markova J, Kahraman D, Kobe C, Skopalova M, Mocikova $\mathrm{H}$, Klaskova $\mathrm{K}$, et al. Role of [18F]-fluoro-2-deoxy-D-glucose positron emission tomography in early and late therapy assessment of patients with advanced Hodgkin lymphoma treated with bleomycin, etoposide, adriamycin, cyclophosphamide, vincristine, procarbazine and prednisone. Leuk Lymphoma (2012) 53:6470. doi:10.3109/10428194.2011. 603444

103. Gallamini A, Patti C, Viviani S, Rossi A, Fiore F, Di Raimondo F, et al. Gruppo ItalianoTerapie Innovative nei Linfomi (GITIL) early chemotherapy intensification with BEACOPP in advanced-stage Hodgkin lymphoma patients with interim-PET positive after two ABVD courses. $\mathrm{Br} J$ Haematol (2011) 152:551-60. doi:10.1111/j. 1365-2141.2010.08485.x

104. Radford J, Barrington S, Councell N, Pettengell R, Johnson P, Wimperis $\mathrm{J}$, et al. Involved field radiotherapy versus no further treatment in patients with clinical stages IA and IIA Hodgkin lymphoma and a 'negative' PET scan after 3 cycles ABVD. Results of the UK NCRI RAPID Trial 54th ASH Annual Meeting (2012). Abstract $547 \mathrm{p}$.

105. Haioun C, Itti E, Rahmouni A, Brice P, Rain JD, Belhadj K, et al. [18F]Fluoro-2-deoxy-D-glucose positron emission tomography (FDG-PET) in aggressive lymphoma: an early prognostic tool for predicting patient outcome. Blood (2005) 106: 1376-81. doi:10.1182/blood2005-01-0272

106. Mikhaeel NG, Hutchings M, Fields PA, O'Doherty MJ, Timothy AR. FDG-PET after two to three cycles of chemotherapy predicts progression-free and overall survival in high-grade non-Hodgkin lymphoma. Ann Oncol (2005) 16:1514-23. doi:10.1093/annonc/ mdi272

107. Spaepen K, Stroobants S, Dupont P, Vandenberghe P, Thomas J, de GrootT, et al. Early restaging positron emission tomography with (18)Ffluorodeoxyglucose predicts outcome in patients with aggressive non-Hodgkin's lymphoma. Ann Oncol (2002) 13:1356-63. doi:10.1093/annonc/mdf256

108. Casasnovas RO, Meignan M, Berriolo-Riedinger A, Bardet S, Julian A, Thieblemont C, et al. SUVmax reduction improves early prognosis value of interim positron emission tomography scans in diffuse large B-cell lymphoma. Blood (2011) 118:37-43. doi:10.1182/blood-2010-12327767

109. The Lymphoma Academic Research Organisation. GA in Newly Diagnosed Diffuse Large $B$ Cell Lymphoma (GAINED) (NCT01659099) (2012). Available from: http://www.clinicaltrials. gov/ct2/show/NCT01659099? term $=$ GAINED $\% 2 \mathrm{C}+\mathrm{PET} \% 2 \mathrm{C}+$ casasnovas\&rank $=1$

110. Quddus F, Armitage JO. Salvage therapy for Hodgkin's lymphoma. 
Cancer J (2009) 15:161-3. doi:10. 1097/PPO.0b013e3181a1438a

111. Engert A, Eichenauer DA, Dreyling M. Hodgkin's lymphoma: ESMO clinical recommendations for diagnosis, treatment and follow-up. Ann Oncol (2009) 20(Suppl 4):108-9. doi:10.1093/annonc/mdp144

112. Friedberg JW, Mauch PM, Rimsza LM, Fisher RI. Non-Hodgkin's lymphomas. 8th ed. In: DeVita VT, Lawrence TS, Rosenberg SA editors. DeVita, Hellman, and Rosenberg's Cancer: Principles and Practice of Oncology. Philadelphia, PA: Lippincott Williams \& Wilkins (2008). p. 2098-166.

113. Terasawa T, Nihashi T, Hotta T, Nagai H. 18F-FDG PET for posttherapy assessment of Hodgkin's disease and aggressive Non-Hodgkin's lymphoma: a systematic review. J Nucl Med (2008) 49:13-21. doi:10.2967/jnumed.107.039867

114. Goldschmidt N, Or O, Klein M, Savitsky B, Paltiel O. The role of routine imaging procedures in the detection of relapse of patients with Hodgkin lymphoma and aggressive nonHodgkin lymphoma. Ann Hematol (2011) 90:165-71. doi:10.1007/s00277-010-1044-8

115. Zinzani PL, Stefoni V, Tani M, Fanti S, Musuraca G, Castellucci P, et al. Role of [18F]fluorodeoxyglucose positron emission tomography scan in the follow-up of lymphoma. J Clin Oncol (2009) 27:1781-7. doi:10.1200/JCO.2008. 16.1513

116. Lee AI, Zuckerman DS, Van denAbbeeleAD, Aquino SL, Crowley D, Toomey C, et al. Surveillance imaging of Hodgkin lymphoma patients in first remission: a clinical and economic analysis. Cancer (2010) 116:3835. doi:10.1002/ cncr. 25240

117. Josting A, Diehl V. Current treatment strategies in early stage Hodgkin's disease. Curr Treat
Options Oncol (2003) 4:297-305. doi:10.1007/s11864-003-0005-z

118. Cheson B. The case against heavy PETing. J Clin Oncol (2009) 11:1742-3. doi:10.1200/JCO.2008. 20.1665

119. Juweid ME, Stroobants S, Hoekstra OS, Mottaghy FM, Dietlein M, Guermazi A, et al. Use of positron emission tomography for response assessment of lymphoma: consensus of the imaging Subcommittee of International Harmonization Project in lymphoma. J Clin Oncol (2007) 25:571-8. doi:10. 1200/JCO.2006.08.2305

120. Spaepen K, Stroobants S, Dupont P, Bormans G, Balzarini J, Verhoef $\mathrm{G}$, et al. [(18)F]FDG PET monitoring of tumour response to chemotherapy: does [(18)F]FDG uptake correlate with the viable tumour cell fraction? Eur J Nucl Med Mol Imaging (2003) 30: 682-8. doi:10.1007/s00259-0031120-6

121. Han HS, Escalón MP, Hsiao B, Serafini A, Lossos IS. High incidence of false-positive PET scans in patients with aggressive non-Hodgkin's lymphoma treated with rituximab-containing regimens. Ann Oncol (2009) 2:309. doi:10.1093/annonc/mdn629

122. Kostakoglu L, Goldsmith SJ, Leonard JP, Christos P, Furman RR, Atasever T, et al. FDGPET after 1 cycle of therapy predicts outcome in diffuse large cell lymphoma and classic Hodgkin disease. Cancer (2006) 107:2678-87. doi:10.1002/cncr. 22276

123. Barrington SF, Qian W, Somer EJ, Franceschetto A, Bagni B, Brun E, et al. Concordance between four European centres of PET reporting criteria designed for use in multicentre trials in Hodgkin lymphoma. Eur J Nucl Med Mol Imaging (2010) 37:1824-33. doi:10. 1007/s00259-010-1490-5

124. Meignan M, Gallamini A, Haioun C. Report on the First
International Workshop on interim-PET scan in lymphoma. Leukemia Lymphoma (2009) $\mathbf{5 0}$ 1257-60. doi:10.1080/ 10428190903040048

125. Biggi A, Gallamini A, Chauvie S, Hutchings M, Kostakoglu L, Gregianin $\mathrm{M}$, et al. International validation study for interim PET in ABVD-treated, advanced-stage Hodgkin lymphoma: interpretation criteria and concordance rate among reviewers. J Nucl $\mathrm{Med}$ (2013) 54:683-90. doi:10.2967/ jnumed.112.110890

126. Lin C, Itti E, Haioun C, Petegnief Y, Luciani A, Dupuis J, et al. Early 18F-FDG PET for prediction of prognosis in patients with diffuse large B-cell lymphoma: SUVbased assessment versus visual analysis. J Nucl Med (2007) 48: 1626-32. doi:10.2967/jnumed. 107.042093

127. Diehl V, Re D, Harris NL, Mauch PM. Hodgkin lymphoma. 8th ed. In: DeVita VT, Lawrence TS, Rosenberg SA editors. DeVita, Hellman, and Rosenberg's Cancer: Principles and Practice of Oncology. Philadelphia, PA: Lippincott Williams \& Wilkins (2008). p. 2167-213.

128. Hatt M, Cheze Le Rest C, Pradier O, Visvikis D. Automatic PET tumour delineation for patient's follow-up and therapy assessment. $\mathrm{J} \mathrm{Nucl}$ Med (2009) 50:182.

129. Hatt M, Visvikis D, Albarghach NM, Tixier F, Pradier O, Chezele RestC. Prognostic value of $18 \mathrm{~F}$ FDG PET image-based parameters in oesophageal cancer and impact of tumour delineation methodology. Eur J Nucl Med Mol Imaging (2011) 38:1191-202. doi:10.1007/ s00259-011-1755-7

130. Werner-Wasik M, Nelson AD, Choi W, Arai Y, Faulhaber PF, Kang $\mathrm{P}$, et al. What is the best way to contour lung tumors on PET scans? Multiobserver validation of a gradient-based method using a NSCLC digital PET phantom. Int
J Radiat Oncol Biol Phys (2012) 82:1164-71. doi:10.1016/j.ijrobp. 2010.12.055

131. Song MK, Chung JS, Shin HJ, Lee SM, Lee SE, Lee HS, et al. Clinical significance of metabolic tumor volume by PET/CT in stages II and III of diffuse large B cell lymphoma without extranodal site involvement. Ann Hematol (2012) 91:697-703. doi:10.1007/s00277011-1357-2

132. Song MK, Chung JS, Shin HJ, Moon JH, Lee JO, Lee HS, et al. Prognostic value of metabolic tumor volume by PET/CT in primary gastrointestinal diffuse large B cell lymphoma. Cancer Sci (2012) 103:477-82. doi:10.1111/j. 1349-7006.2011.02164.x

Conflict of Interest Statement: The authors declare that the research was conducted in the absence of any commercial or financial relationships that could be construed as a potential conflict of interest.

Received: 10 April 2013; paper pending published: 05 July 2013; accepted: 02 August 2013; published online: 04 September 2013.

Citation: Kostakoglu L and Cheson BD (2013) State-of-the-art research on "lymphomas: role of molecular imaging for staging, prognostic evaluation, and treatment response". Front. Oncol. 3:212. doi: 10.3389/fonc.2013.00212

This article was submitted to Cancer Imaging and Diagnosis, a section of the journal Frontiers in Oncology.

Copyright (C) 2013 Kostakoglu and Cheson. This is an open-access article distributed under the terms of the Creative Commons Attribution License (CC BY). The use, distribution or reproduction in other forums is permitted, provided the original author(s) or licensor are credited and that the original publication in this journal is cited, in accordance with accepted academic practice. No use, distribution or reproduction is permitted which does not comply with these terms. 